\title{
Crisis mundial sanitaria: oportunidad para pensar al ciudadano dentro del sistema neoliberal peruano
}

\author{
Apuntes de Investigación \\ Recibido: 24/09/2020 \\ Aprobado: 20/10/2020 \\ Publicado: 05/02/2021
}

\author{
Martha Kruskaya Vigo Castilla \\ Universidad Nacional Mayor de San Marcos \\ martha.vigo@unmsm.edu.pe
}

\begin{abstract}
RESUMEN
La crisis actual producto de la pandemia ha develado aquellos problemas económicos y sociales que siguen siendo parte de la estructura del Estado peruano. Pobreza, discriminación, corrupción, servicios de salud, educación y seguridad precarios, burocracia estatal, etc., así como las grandes brechas socioeconómicas que se reflejan en las diferentes condiciones con que las familias están enfrentando la pandemia. El aprovechamiento de la posición de poder por parte de las élites empresariales en nuestro país permite la práctica antidemocrática dentro del sistema tributario, el cual favorece a los más poderosos, mientras perjudica y castiga la informalidad en la que se encuentra la mayor parte de la clase trabajadora de nuestro país. A pesar de la difícil situación sanitaria que se padece, es necesario enfocar el debate en la condición en la que el ciudadano se encuentra dentro de éste paradigma neoliberal peruano, cuáles son sus derechos y deberes, e intentar vislumbrar cómo podría lidiarse con un futuro cercano post pandemia para intentar reescribir la historia, desde los hogares, el trabajo, las escuelas y en la escena política; a fin de no repetir viejos errores del pasado y presente, manteniendo la esperanza de un mayor bienestar en base a la democracia y la justicia social.
\end{abstract}

Palabras Clave: ciudadano; neoliberalismo; pandemia; pobreza; democracia; justicia social.

\section{World health crisis: opportunity to think the citizen within the Peruvian neoliberal system}

\begin{abstract}
The current crisis product of the pandemic has revealed those economic and social problems that continue to be part of the structure of the Peruvian State. Poverty, discrimination, corruption, precarious health services, education and security, state bureaucracy, etc., as well as the large socioeconomic gaps that are reflected in the different conditions with which families are facing the pandemic. The use of the position of power by business elites in our country allows undemocratic practice within the tax system, which favors the most powerful, while harming and punishing the informality in which most of the class finds itself worker of our country. Despite the difficult health situation that is suffered, it is necessary to focus the debate on the condition in which the citizen is within this Peruvian neoliberal paradigm, what are their rights and duties, and try to glimpse how they can deal with a near future post pandemic to try to rewrite history, from homes, work, schools and on the political scene; in order not to repeat old mistakes of the past and present, maintaining the hope of a greater well-being based on democracy and social justice.
\end{abstract}

Keywords: Citizen; Neoliberalism; Pandemic; Poverty; Democracy; Social Justice. 


\section{Introducción}

L a crisis sanitaria mundial actual producto de la pandemia por el Covid-19 ha develado el nivel de capacidad y de estrategias de cada país para enfrentarla, dentro de un sistema mundo donde el libre mercado es su principal condición de funcionamiento. Si bien las medidas tomadas por los países son básicamente similares, debido a que siguen los parámetros y recomendaciones brindados por la Organización Mundial de la Salud; no todos las han implementado de la misma forma, y por consecuencia, no se han obtenido los mismos resultados. Cuarentenas prorrogadas cercanas a cumplir los nueve meses, prohibiciones para salir de los hogares, paralización de la mayoría de las actividades empresariales, suspensión de las actividades educativas y culturales presenciales en todos los niveles, paralización del transporte internacional y limitaciones para el transporte interprovincial, además de la suspensión de las actividades turísticas, estrictas restricciones para el servicio en restaurantes, y migración hacia la actividad virtual o remota de la mayoría de las labores administrativas del Estado; figuran entre las principales políticas de seguridad para evitar la propagación del virus entre las personas.

El Estado peruano, dentro de todas estas estrategias para enfrentar la extensión de la enfermedad y evitar que el país entre a un colapso económico, social y político, ha realizado esfuerzos denotados que han demostrado el compromiso de las autoridades, sobre todo del Ejecutivo, para tratar de salir de la situación en el menor tiempo posible. Sin embargo, las evidencias que la realidad demuestra en las diversas regiones del país a través de los diversos medios de comunicación con respecto al colapso en el sistema de salud pública, además del incremento de la tasa de desempleo por la incapacidad de las empresas para mantener el costo de sus planillas sobre todo dentro del sector informal el cual representa poco menos del $80 \%$ de toda la actividad empresarial del país, el alza del precio de balones de oxígeno por ser un suministro fundamental para la sobrevivencia del enfermo, así como una cifra de fallecidos mayor a los treinta mil compatriotas, figuran entre las principales consecuencias que deja la pandemia en lo que va del año. Cabe mencionar también, no por menos importante, el incremento de la cifra de feminicidios, que duran- te toda la etapa de la cuarentena hasta agosto han ocurrido alrededor de 37 muertes, según indica el gobierno, sin mencionar aquellas aún en proceso de investigación.

Todo este panorama de incertidumbre en nuestro país invita a cuestionarse el por qué las consecuencias de esta pandemia afectan de forma desigual a los diferentes segmentos sociales, evidenciándose con total claridad quienes son aquellos que tienen las condiciones materiales para refugiarse en sus hogares y cuidarse del contagio con mayor efectividad que aquellas grandes mayorías que viven en condiciones precarias, que necesitan salir a las calles a trabajar debido a que sus ingresos de sobrevivencia se generan de forma diaria y la mayoría pertenece al sector informal; aquellos que no consiguen camas en los hospitales públicos ni oxígeno para sobrevivir, y que además viven en hogares donde existe la violencia tanto física como psicológica dentro de los cuales niños y jóvenes están obligados a convivir con padres o abuelos durante las 24 horas, enfermándose psicológicamente; evidenciándose en la presencia de cuadros de ansiedad, depresión y demás enfermedades mentales, según indica la Organización Panamericana de la Salud. Cabe con todo ello, pensar en qué se está fallando y el por qué nuestro país se encuentra a puertas de la celebración del bicentenario de la independencia y sigue arrastrando las grandes desigualdades sociales, normalizando las diferencias en oportunidades y condiciones, otorgándosele toda la responsabilidad al gobierno y evitando asumir una postura crítica que permita, desde los distintos frentes, hacer esfuerzos para resolver estos problemas de los cuales nadie, ni mucho menos las minorías privilegiadas, deberían sentirse ajenas ni indiferentes.

Para empezar a pensar la situación planteada, primero debemos reconocer quienes somos como peruanos, cuáles son nuestros derechos y deberes, hacia donde vamos, no sólo como individuos y familias aisladas, sino como un colectivo que debe reconocer sus intereses comunes y trabajar para alcanzar objetivos generales que generen una verdadera identidad peruana; lejos de la exclusión y la injusticia social.

Los derechos y deberes en común que compartimos todos los peruanos nos convierten ante el Estado en ciudadanos, en su concepción más amplia, y relacionada con la igualdad ante la ley y la garantía de los derechos amparados en la Constitución, dentro de 
un sistema institucional, político, económico y social que se rige bajo los principios del libre mercado, y que otorga primordial importancia a la estructura económica y productiva como base fundamental de todo el restante orden político y social. Cabe comprender y reconocer al Neoliberalismo como aquel sistema donde el ciudadano peruano, dentro de las condiciones originarias en que le toca vivir, responde ante su realidad, buscando desarrollarse dentro de las posibilidades de vida que pueda alcanzar, sean estas precarias o privilegiadas.

El ciudadano peruano, reconocido formalmente por la Constitución, sortea su destino dentro de un país que lo arroja al mercado en todos los ámbitos de su vida, sometiéndose a que el valor de su persona sea determinado según las necesidades del mercado, en cuyo espacio se desenvuelve alrededor de un contexto marcado por la incertidumbre que generan los contratos laborales temporales, servicios públicos que al ser comparados con los privados se refleja una brecha de calidad escandalosa, pensiones de jubilación que no son un problema en sí mismos sino la consecuencia de la poca importancia que el Estado le otorga a la educación, ciencia y tecnología, lo cual se refleja en los bajos niveles de productividad de las personas y en las precarias pensiones previsionales para vivir la vejez. Además de lo mencionado, se suma la burocracia estatal, administrativa, tributaria, judicial, municipal, educativa, entre otras, que limita a que el ciudadano pueda aspirar a desarrollar todas sus habilidades y emprender para salir de la pobreza y contribuir a la economía a través de su trabajo, reducir las cifras de conflictos sociales, y alcanzar un desarrollo humano digno de un país de primer mundo.

La crisis de la pandemia en el Perú, a pesar de los fallecidos por la enfermedad del Covid-19 y las duras consecuencias económicas que deja a su paso; debe ser tomada en lo que va del momento en adelante, como una oportunidad para sacar a la luz los viejos problemas sociales que retrasan el avance del país, y reflejan que solamente con limitarse a tener una macroeconomía sólida no es garantía para sentir que se ha logrado lo suficiente. Mientras los gobiernos de turno, los gremios de las empresas más poderosas, y las elites minoritarias del país, no comprendan que debe colocarse a los ciudadanos peruanos en el centro de las políticas públicas por encima de la estructura económica capitalista, e insistan en continuar con la misma fórmula neoliberal para administrar al país; seguiremos celebrando a variables económicas agregadas que crecen en términos numéricos y monetarios, pero que no reflejan la desigual distribución de la riqueza, la falta de oportunidades para las grandes mayorías; y esconden la realidad de un Estado fallido, pero maquillado por fuera, con intenciones de ingresar al grupo de la Organización para la Cooperación y Desarrollo Económico (OCDE) y poder aspirar a elaborar metas que nos empujen hacia el nivel de desarrollo de los países del primer mundo.

El presente artículo pretende invitar a enfocar la atención en la condición del Neoliberalismo en el Perú durante la crisis por la Pandemia, y analizar aquellas políticas que se están llevando a cabo las cuales reflejan la falta de solidez y compromiso social cuando se presentan situaciones tales como la presente crisis sanitaria; es básicamente una excusa para reconocer cuál es la posición del ciudadano peruano dentro del sistema de libre mercado, sobre todo en situaciones que ponen en riesgo a la economía y a la vida de las personas, así como intuir cual es la consideración que tiene el gobierno frente a la sociedad en su conjunto; si somos parte de la preocupación central de todas sus políticas para enfrentar la crisis sanitaria, o solamente una obligación que cumplir para mantener a flote al sistema económico institucionalizado desde hace 30 años y que constituye la principal preocupación para los actores políticos y los más grandes gremios económicos del país.

Trabajos relacionados a la presente serán de gran apoyo para reafirmar las propuestas que se pretenden difundir y que buscan contribuir con la toma de conciencia al servicio de la comunidad estudiantil y académica. El artículo denominado "Coronavirus y neoliberalismo en el Perú” de Anahí Durand Guevara para el Centro de Análisis político CELAG, de abril del 2020, permite conocer con riguroso análisis político las difíciles secuelas económicas, políticas y sociales que deja a su paso la pandemia dentro del marco de globalización económica. Asimismo, se enfatiza en las consecuencias que trae el hecho de no replantearse modificar ciertas políticas de libre mercado las cuales revelan sus inconsistencias en épocas de crisis.

Por otro lado, el artículo titulado "Los futuros posibles e imposibles de la pandemia" de Nicolás Lynch para el Portal la Otra Mirada, de junio de 2020 , aporta al debate la necesidad de tomar la opor- 
tunidad después de la pandemia de redirigir la política hacia una mayor participación de aquellos grupos políticos que de momento se encuentran al margen del escenario político y que pueden, desde una posición desinteresada y coherente con la realidad, aportar con sus ideas a mejorar las condiciones del país y renovar la institucionalidad democrática, demostrando que si seguimos confiando el destino del Estado a los mismo cuadros políticos tradicionales, seguiremos arrastrando los mismo problemas que hacen del Perú una república inconclusa en su construcción.

Asimismo, para contrarrestar las opiniones analizadas en la presente, se contará con el análisis de Roberto Abusada en una entrevista para El Comercio de noviembre del 2019 denominada "¿Perú neoliberal?”, donde el economista cuestiona la existencia del Neoliberalismo en el Perú alegando que a lo que llamamos de esa manera no es sino un libre mercado con altos niveles de participación Estatal ineficiente, al que se le debe la responsabilidad y causa de todos los problemas económicos y sociales que forman parte de la cultura política del país; separando de la responsabilidad a los demás agentes económicos que participan en el mercado y a aquellos grupos de poder económicos que influyen en las decisiones dentro de la agenda política de cada gobierno de turno desde hace 30 ańos.

Es importante también analizar el artículo de Marcos Cueto para el Instituto de Estudios Peruanos denominado "La Covid-19 y las epidemias del neoliberalismo" de marzo del 2020, donde el autor plantea que la crisis de la pandemia actual y otras enfermedades masivas mundiales son consecuencias del ánimo de lucro de los grupos de poder, por encima de cualquier política social que busque la garantía de los principales derechos sociales como el de la salud. Además de ello, el Neoliberalismo es señalado como el causante de la degradación del medio ambiente y los principales conflictos sociales; sumándose a ello la condición de discriminación, la cual dificulta la capacidad del gobierno de reconocer la importancia de la igualdad ante la ley para el sostenimiento de un Estado de derecho que permita la convivencia pacífica en equidad de oportunidades entre las personas a fin de poder alcanzar un nivel de desarrollo económico y social sostenible.

Otro importante análisis a considerar en la presente es el de Alonso Marañón para CLACSO de- nominado "Un mes de cuarentena en Perú: anormalidad, Estado y neoliberalismo" de abril del 2020, donde el autor realiza una descripción de la grave situación en la que se encuentra el país debido a la emergencia sanitaria, donde la incertidumbre de la población por su propia salud se une a la preocupación por la pérdida de puestos de trabajo y la reducción progresiva, y en mayores casos fulminante, de los ingresos económicos familiares. Asimismo el autor resalta la importancia de develar el por qué aún se difunde y se implanta como una verdad la idea de que el modelo neoliberal es el más exitoso y única vía para el porvenir del país, mientras que los resultados de las políticas implementadas en estos ańos de etapa Neoliberal no han alcanzado los objetivos de desarrollo social prometidos, sino más bien han llevado al país a la condición de un Estado débil, sin capacidad de tomar decisiones en base a razones e intereses colectivos en favor de las mayorías.

Por último, es pertinente también realizar un análisis del artículo de Rodrigo Montoya denominado "Aquí termina Lima" del libro El Coronavirus y su impacto en la sociedad actual y futura, publicado en mayo del 2020 por el Colegio de Sociólogos del Perú, donde el autor plantea la problemática del centralismo, y cómo ésta influye en la propagación de los contagios principalmente en la capital del país, debido al hacinamiento producto de la migración de la población provinciana a Lima, la cual, albergando la esperanza de un futuro donde puedan aspirar a mejorar su calidad de vida, dentro de la ilusión que vislumbra a la capital como la ciudad de las oportunidades; éstos se enfrentan a un ideario que la pandemia ha develado como falso, debido a las condiciones de precariedad en la que se encuentran la mayoría de los distritos de Lima para enfrentar la propagación del virus; la informalidad, el desempleo y el nivel precario de saneamiento y atención a la salud, que pone en riesgo de contagio a los residentes en la capital.

\section{Metodología}

El presente artículo de investigación se ubica a nivel explicativo en tanto se propone determinar las causas y consecuencias de la desigualdad de condiciones en la que los ciudadanos se desenvuelven dentro del sistema de vida neoliberal, específicamente duran- 
te la situación de la crisis sanitaria por la pandemia del Covid-19. Asimismo, según los datos utilizados, se considera una investigación cualitativa, no experimental.

\section{Resultados y discusión}

La crisis que vive el país producto de la pandemia por Covid-19 ha demostrado que las políticas de gobierno que se han implementado estos últimos 30 años de regímenes neoliberales son sostenibles sólo en periodos de estabilidad económica mundial, lo cual afecta en forma directamente proporcional a la economía nacional a través de la variación del precio de los principales commodities que el país exporta al mundo; develando cómo funciona, desde la perspectiva económica comercial, el paradigma de la globalización, el cual sitúa al Perú dentro de la división internacional del trabajo como país proveedor de materias primas al servicio de los países industrializados, los cuales cuentan con mayores niveles de producción a gran escala de bienes con alto valor agregado.

Con estas aseveraciones no se pretende solamente pensar al Perú condenándolo a un papel de subordinación inevitable dentro del sistema mundo moderno, a pesar de que la realidad nos condicione a ser un país primo exportador por necesidad cortoplacista para mantener la estabilidad económica actual dentro de la estructura económica establecida en los últimos años; sino más bien, se debe ir a mayor profundidad en el análisis para señalar a los principales responsables que pretenden, de forma consciente, pero en mayor medida guiándose de una inconsciencia animada por la ambición y el principio aprendido o innato de egoísmo e individualismo; que la categoría de país de tercer mundo se convierta en una condición cualitativa permanente e imposible de ser superada.

Para Durand (2020) la situación de pandemia actual devela aquellos problemas inconclusos que se han ido normalizando con los años debido a la preocupante lentitud con la que los gobiernos de turno de éstos últimos 30 años han actuado y no le han dado la verdadera importancia y voluntad para darles solución. El precario e ineficiente sistema de salud pública que se refleja en el insuficiente número de camas para las unidades de cuidados intensivos y balones de oxígeno, en la poca capacidad para obtener mate- riales médicos lo que aumenta el riesgo de contagio para el personal médico, en la cantidad de fallecidos que mueren por enfermedades preexistentes perfectamente curables si hubiera existido previamente una mayor preocupación del Estado por incentivar la cultura de la prevención en salud y una mayor cobertura y calidad de atención para la sanidad de la población.

Lo que está reflejando la crisis sanitaria actual es, simplemente, todos estos ańos de negligencia e indiferencia que los gobiernos neoliberales han perdido, debido a que su foco de atención se sigue manteniendo en mirar, atender e incentivar el crecimiento de ciertos agregados macroeconómicos que sólo generan beneficios para las grandes empresas nacionales y transnacionales, pero que no explican la situación de precariedad económica y social de la población restante sujeta a su propia realidad microeconómica, es decir; la economía del día a día, de lo inmediato, de lo urgente e imprescindible para la sobrevivencia de las grandes mayorías empobrecidas del país.

Otra de las cuestiones que plantea Durand (2020) es que el gobierno, conociendo la realidad de la informalidad generalizada en nuestro país, aun no tiene un planteamiento claro y objetivo para darle solución al problema. Una respuesta aproximada a la cuestión podría encontrarse en que el problema no ha sido atendido — salvo por medidas de fuerza policial y fiscalización municipal que apelan a la coacción y a la violencia - porque de alguna manera es una situación que conviene a ciertos grupos empresariales y políticos, los cuales dependen de la informalidad para realizar sus actividades dentro de su propia cadena productiva; por ejemplo, una empresa formal cuenta muchas veces con proveedores informales con los cuales puede transar de forma deliberada al margen de la ley con el objetivo de abaratar sus costos y poseer facilidades en tramitación. Asimismo, las empresas informales no constituyen una verdadera competencia para las grandes empresas debido a que la posibilidad de crecimiento de las primeras tiene un tope establecido incapaz de acercarse a la legalidad. Además de ello, los informales se ven impedidos de recibir apoyos económicos del Estado, situación que le permite al gobierno deslindarse de responsabilidades de forma indirecta y dejar que cada agente económico se salve por su cuenta, y como pueda, en la intensa competencia del mercado. 
No volver a lo mismo es la consigna de aquellos quienes creen en una verdadera posibilidad de renovación y reestructuración del sistema económico que supere el paradigma promovido con mucha constancia por ciertos especialistas e intelectuales orgánicos promotores del libre mercado, quienes insisten, utilizando sus influencias para la difusión de su discurso, el mantener el modelo neoliberal tal y como está estructurado, en base a intereses individuales, diferencias de clase, discriminación, desigual distribución de ingresos, y privilegios tributarios otorgados por el gobierno a las grandes empresas; que conducen al país hacia un Estado fallido.

Podemos avanzar con cerrar el ciclo asegurándonos de no volver a lo mismo, ensanchando el espacio para garantizar lo público sobre la base de la solidaridad, la comunidad en torno al cuidado mutuo; esa reciprocidad a la que seguramente apelaron nuestros antepasados para derrotar antiguas pandemias. (Durand 2020: s. p).

La crisis de la pandemia actual reabre también una oportunidad para proyectar el posible escenario político a futuro de cara al bicentenario. Este ejercicio de pronóstico es importante debido a que todas las personas, cualquiera sea el frente en que se encuentren, son responsables de trabajar y contribuir con la conducción del país de acuerdo con principios colectivos y solidarios.

El Estado es el espacio donde se concentran las razones públicas, tal y como lo manifestaba el filósofo Hegel, al considerarlo como una dimensión dirigida por ciertos hombres altamente ilustrados en mente y espíritu, pero cuyas decisiones deben reflejar los más elevados valores de la vida humana, y cuya omnipotencia nos permite acercarnos al espíritu de la sabiduría absoluta que posee la verdad, la razón y la respuesta a todos los problemas del país. Aunque no se pretende idealizar el rol del Estado en absoluto, es necesario encontrar la utilidad que su capacidad de concentración de poder le permite para la toma de decisiones políticas que alcancen ciertos objetivos colectivos y una verdadera justicia social.

Para Lynch (2020) en la actual disputa política por el poder, dentro del marco de la crisis sanitaria, se encuentran aquellos que intentan con todos sus esfuerzos mantener la misma estructura neoliberal tradicional, la cual por ostentar el poder comunicacional, difunden por medio de sus intelectuales or- gánicos los logros de aquella doctrina que defiende al libre mercado, la privatización de los capitales y el privilegio de las minorías, y que además promocionan el éxito de los últimos treinta años de neoliberalismo — evitando mencionar el término como tal— justificándose en base al incremento de las cifras macroeconómicas, como por ejemplo el crecimiento sostenido del Producto Bruto Interno a ritmos de entre el 2\% al $4 \%$ en promedios anuales, y el incremento de las exportaciones como principales caballos de batalla.

Estos defensores del modelo neoliberal se han visto perjudicados debido a la conducta poco solidaria que han demostrado sus principales miembros, como las AFP, al negarse a reducir las comisiones y seguros que cobran de las pensiones de sus clientes, además de mostrarse en contra de las propuestas del congreso sobre la devolución de una parte de los fondos acumulados para que sus afiliados puedan sortear la crisis económica producto de la pandemia. Asimismo, los bancos por su parte han mostrado una actitud reacia a congelar los créditos en lo que dure el periodo de cuarentena, y que para evitar que la población les genere un mayor rechazo, se han visto obligados a refinanciar las deudas y aplazar los intereses generados hacia cuotas posteriores, si sólo si, el Estado les otorgue un rescate económico suficiente dentro del plan de Reactiva Perú, que financia y apoya también a las empresas en general. Las clínicas por su parte al cobrar tarifas elevadas, los colegios privados al negarse a reducir sus pensiones a pesar de la migración hacia la educación remota, las farmacias al elevar el costo de los medicamentos y evitar ofrecer alternativas genéricas que puedan ayudar a los bolsillos de las familias; son sólo algunos ejemplos de ciertos grupos de poder que intentan evitar que sus capitales excedentes se pongan en riesgo en lo que dura el Estado de Emergencia sanitaria y la paralización de ciertas actividades económicas que los perjudiquen.

Dentro del otro grupo que disputa el poder según Lynch (2020) están aquellos quienes actualmente lo ostentan, es decir, aquellos que apoyan al Presidente Vizcarra y sus políticas mínimamente reformistas, las cuales han realizado ciertos cambios para beneficio social, que aunque insuficientes, intentan tímidamente confrontar a los grupos de poder empresariales, pero cuyos resultados sólo hacen que estos esfuerzos sean relacionados con intenciones populistas y tibias que no alcanzan a generar sino progresos superficiales que 
no cuestionan las bases sistémicas neoliberales que perpetúan las desigualdades y la pobreza, limitan a la democracia y nos alejan de la justicia social.

Por último, según menciona Lynch (2020) se encuentran aquellos actores políticos de izquierda cuyo rol se ha limitado por muchos años a una suerte de oposición minoritaria al régimen neoliberal, con presencia dentro de los poderes del Estado, sobre todo en el Parlamento; impedidos para incluir sus propuestas dentro de la agenda política, por razones de ser relegados y rechazados debido a que representan lo que significaría una modificación de las bases que sostienen al sistema actual, una redefinición de las prioridades del gobierno hacia lo colectivo, una mayor participación Estatal como garante de un libre mercado verdaderamente democrático en camino hacia un Estado de Derecho donde la vida humana y el medio ambiente sean reivindicados y exijan la garantía de sus derechos para alcanzar una vida digna para todos. Lamentablemente, pero sin intenciones de imposibilitar una esperanza hacia los próximos comicios generales del 2021, los principales grupos de izquierda y sus representantes aún no encuentran aquellos ángulos a través de los cuales puedan articular un proyecto en conjunto.

Mientras no se admita debatir temas como la renta básica universal, la desaparición de las AFP y el cambio constitucional, se alimentará la polarización y se agudizará la precariedad democrática. Sólo la entrada de nuevos actores con otra orquesta que toque los temas populares permitirá una salida democrática al país. (Lynch 2020: s. p).

Existen también opiniones diversas que cuestionan la existencia del neoliberalismo, y que son de interesante análisis debido a que constituyen la antítesis que contrasta la concepción neoliberal, y que además resulta incluso necesario para entender a mayor profundidad a que se le suele definir como neoliberalismo; con la finalidad de analizar de forma más objetiva e intuitiva cómo aquellos fenómenos aleatorios o premeditados de forma indirecta como las crisis, en este caso específico la crisis por la pandemia del Covid-19, afectan de forma desigual y generan la exacerbación y agudización de los conflictos de convivencia previamente existentes, como son la desigualdad, la pobreza, discriminación, delincuencia, corrupción, para mencionar sólo los principales.
Para Abusada (2019) la agudización de los conflictos mencionados en el párrafo anterior es utilizado como una excusa por los grupos de la izquierda como la representación de un caos necesario para hacer comprender a la población en general de la necesidad de una transformación radical del sistema económico institucionalizado. Por el contrario, el economista considera que estos últimos treinta años de regímenes bajo el principio del libre mercado han supuesto un avance enorme en materia económica y social que ningún otro tipo de proyecto político, mucho menos aquellos que promueven el estatismo, podría haber logrado.

Es fácil ver que lo que se ha descrito son las características propias de todas las economías que han alcanzado el progreso económico y social. Sin embargo, se trafica demagógicamente con el anhelo ciudadano por mayor seguridad, servicios básicos, empleo, igualdad de oportunidades e igualdad ante la ley. El cambio constitucional se vende como la panacea para alcanzar ese anhelo, cuando el único objetivo es satisfacer el ansia estatista y totalitaria de sus proponentes. (Abusada 2020: s. p).

Asimismo, el autor le atribuye el lento e insuficiente crecimiento económico y social del país a la incapacidad del Estado de cumplir con las necesidades básicas de la población, además de ponerle constantes trabas a la iniciativa privada que es la responsable de la generación de la mayor parte de la riqueza del país. La burocracia, la corrupción, la falta de productividad del aparato administrativo estatal, la incapacidad para acelerar los procesos de inversión pública, entre otras falencias; son responsabilidad única y exclusiva del Estado.

Sin embargo, Abusada no toma en cuenta que el Estado no actúa sólo, sino que es un elemento dentro del juego de poder que comparte con los grandes grupos económicos, con los cuales se elabora una agenda país alterna que dirige a la política. Es decir, al referirnos al término neoliberalismo no solo se trata de encontrar un único responsable de orquestar todo el proyecto, sino que se debe de comprender como un entramado de intereses que se coluden entre sí para sacar provecho de la acumulación de la mayor parte de las riquezas del país, apropiarse de los recursos naturales, utilizar privilegios para la exoneración de impuestos y aprovecharse de la libertad del mercado para legalizar la concentración del poder en forma 
de prácticas monopólicas, determinar los precios, e incluso establecer el valor de mercado de la mano de obra, aprovechándose de la flexibilidad laborar que permite a los empleadores prescindir de un trabajador para ser reemplazado por otros a menor costo; situación que pone en tela de juicio la garantía de los derechos sociales y debilita los ánimos del trabajador para alcanzar una vida digna.

Con respecto al segmento laboral, estas aseveraciones deben reconocer que es importante que el trabajador posea cualidades físicas y mentales que le permitan responder al mercado con niveles de productividad adecuados que justifiquen un salario justo y progresivo, en base a sus esfuerzos por salir adelante y desarrollarse profesionalmente; es justamente el Estado quien como lo exige reiteradamente los empleadores, el principal responsable de apoyar, promover y generar las condiciones de garantía de los derechos básicos y sociales para que los individuos puedan desarrollar las habilidades necesarias que les permita acceder a una mayor bienestar.

Pero además de ello, el sector privado debe entender que, de seguir manteniendo una postura de buscar privilegios individualistas que requieren de gobiernos alineados a sus consignas, y no permitir que existan propuestas políticas alternas y progresistas que establezcan un orden social y privilegien intereses colectivos y razones públicas que de ninguna manera significan poner en riesgo sus capitales acumulados sino más bien que otorguen a quien le corresponda la riqueza en base al principio democrático de justicia social; entonces seguiremos arrastrando aquellos viejos conflictos que desde hace 200 años se encuentran irresueltos y nos impiden aspirar a ser un país de primer mundo. El principio de solidaridad, hoy más que nunca, debe estar por encima de la tabla de valores dentro de la política, y ser entendido como asumido por las élites económicas del país, sin temor a que esto signifique una confrontación directa hacia sus intereses; sino más bien es una invitación a que formen parte de una gran transformación social que involucre a todos los miembros de la sociedad.

La crisis producto de la pandemia del Covid-19 no es sino una consecuencia directa de las políticas implantadas por el sistema neoliberal a nivel mundial. Así lo asevera Cueto (2020) al realizar una explicación muy analítica en base a la influencia no sólo económica y política del neoliberalismo, sino también a su concepción cultural que se inserta en el ideario del individuo, limitando su capacidad de repensar las alternativas posibles para un cambio estructural que evite aquellas consecuencias negativas que sentencian al país a sufrir de la peor forma una crisis por pandemia que pudo ser manejada con mayor eficiencia y voluntad cooperativa.

La mala decisión de aquellos gobiernos de derecha, que durante estos treinta ańos de libre mercado a ultranza redujeron el gasto social en general, tanto en educación, como en salud, y en programas sociales - que se hayan creado nuevos programas sociales no implica que estos hayan sido entregados de forma adecuada, sino más bien, con insumos y atención precarios - ha generado que las grandes mayorías se vean desprotegidas y vulnerables frente a un Estado que las discrimina, debido a que no los reconoce y ni siquiera los tiene registrados adecuadamente para poder acceder a ofrecerles un apoyo de sobrevivencia temporal; prueba de ello es la ineficiente capacidad del Estado de otorgar los bonos de apoyo económico a las familias vulnerables en situación de pobreza, las cuales tienen que realizar largas colas a riesgo de contagio, para recibir un rescate mensual menor al sueldo mínimo, que no toma en cuenta los gastos en salud y protección que deben hacerse para evitar la propagación del virus.

Las pandemias antes mencionadas surgieron y se agravaron por la discriminación, el deterioro del cambio climático, la violencia contra la naturaleza ejercida por fuerzas extractivas sin regulación y la negación de los derechos humanos, como el derecho a la salud de cualquier persona, que abierta o subrepticiamente glorificó el neoliberalismo. (Cueto 2020: s. p).

Cueto (2020) enfatiza también en el poco interés que los gobiernos populistas de derecha en el país le han otorgado al desarrollo científico y en general a la educación, lo cual nos limita como país a ser dependientes de la importación de conocimiento y de patentes extranjeras, situación que genera una relación de dependencia que más allá del gasto público que implica, refleja la poca capacidad de la población para empoderar su vida en base al conocimiento y la innovación; herramientas que les permitirían no sólo desarrollarse de forma individual, sino que repercuten en el incremento de la productividad económica del país, reducirían la dependencia hacia la producción extranjera, generarían un verdadero desarrollo 
industrial nacional, un incremento en el número de empleos, y por obviedad, un avance hacia el desarrollo humano para la población nacional.

Si bien la inversión pública en ciencia y tecnología representa un gasto presente que trae frutos y ganancias a futuro, no debe dejar de ser prioridad en la agenda pública nacional, cuyos gobernantes de momento se encuentran incapaces de proyectar su visión de país; porque se encuentran encerrados dentro de una concepción mental que sólo les conduce a satisfacer sus intereses particulares e inmediatos, dejándose llevar por el ego y el ánimo de lucro excesivos que los aleja del verdadero sentido de unidad social que involucra al individuo como parte, causa y consecuencia, de un todo colectivo.

Influye también el contexto internacional, que como menciona Cueto (2020) la administración de los Estados Unidos, quien maneja y financia a la Organización Mundial de la Salud, ha decidido bajo la administración de Trump, realizar recortes de financiamiento en perjuicio de la mencionada organización, además de ir eliminando de a pocos los programas sociales de salud que representaban un avance social producto de los esfuerzos durante la administración de Obama; un claro ejemplo para el mundo de la promoción de la privatización de la salud, además de considerarla como un privilegio por el cual se debe pagar, y no como un derecho del ciudadano a gozar de un estado de salud adecuado para vivir con dignidad.

Los defensores del modelo neoliberal alegan que todos estos problemas producto de la pandemia, así como la crisis política que desde el año 2017 viene develando escándalos de corrupción relacionados con el caso Odebrecht los cuales involucran a todos los expresidentes del Perú, al menos dentro del periodo de los años noventa en adelante; son consecuencia de los fallos que inherentemente constituyen al Estado, y que nadie más fuera de esa esfera tiene mayor responsabilidad. Para los críticos al neoliberalismo, estos hechos constituyen la oportunidad de repensar nuestro destino como país, siempre y cuando el acceso al poder se aperture para incluir a nuevos actores políticos con propuestas de progreso y justicia social, "Las contradicciones y fisuras del neoliberalismo ahora son más explícitas que antes. Pero la interpelación siempre es un trabajo político, no automático, cu- yos resultados imprevisibles no son de corto plazo" (Marañón 2020: s. p).

Un aspecto imprescindible de tomar en cuenta, por la envergadura de su tratamiento es sobre la cuestión del centralismo en nuestro país, situación que repercute en la condición de hacinamiento principalmente de la capital Lima, la cual por tales condiciones es la ciudad que ostenta el mayor número de contagios, seguido muy por detrás en cifras por la región Callao, Piura y Lambayeque, según lo publicado por la Sala Situacional del Covid-19 del Ministerio de Salud.

El problema del centralismo en nuestro país resulta una condición de la realidad nacional que tuvo su momento de difusión en los primeros ańos del gobierno de Toledo y que sólo quedo en una tibia reforma departamental que le otorgó autonomía económica a los recién creados gobiernos regionales, con la esperanza de descentralizar no solamente el poder político y administrativo. Lamentablemente, a casi veinte años después de estas reformas, aun no se ve reflejado el avance económico y social que debieran haber alcanzado las veinticinco regiones del país; hecho que se sigue reflejando en las cifras de migraciones hacia Lima, la cual sigue siendo la ciudad de las oportunidades para muchos provincianos que aspiran a mejorar su situación social y que encuentran muy pocas posibilidades dentro de sus lugares de origen.

Una de las cuestiones que deja en claro la pandemia es que la esperanza de un mejor futuro que suponía vivir en Lima se ha revelado como una ilusión que refleja los altos niveles de informalidad, los sueldos precarios, la inseguridad laboral en términos de salud y estabilidad, así como las incongruencias de un Estado que deja al trabajador en manos de sectores informales, lo cuales se ven limitados a retribuirles económicamente de forma digna. Por otro lado, dentro del sector privado, sólo aquellos que puedan cumplir con los requisitos académicos requeridos podrán acceder a un salario por encima del promedio general, los cuales representan una minoría insuficiente para considerar a Lima como la ciudad de las oportunidades.

Se le suma a la situación la discriminación que los ciudadanos provenientes de las provincias padecen en la capital, lo cual resulta un conflicto social absurdo que demuestra un escaso nivel cultural y la poca capacidad de identificación con las diversidades étnicas 
que muchos de los ciudadanos limeños padecen, a razón de la ignorancia y de la ausencia o limitada capacidad del gobierno para difundir, en los ámbitos académicos y educativos en general, la riqueza cultural y diversidad étnica del país.

La condición de discriminación entre peruanos no sólo repercute en la masa poblacional sino también se encuentra enquistada dentro de la mentalidad de los agentes neoliberales, tanto en el gobierno como en los más poderosos gremios empresariales en nuestro país; donde se promueve de generación en generación la cultura de diferenciar a las personas entre ciudadanos que son de "primera clase" y aquellos que no lo son, como lo mencionase así el expresidente Alan García, al referirse sobre éstos últimos a los miembros de las comunidades indígenas, en su lucha por el respeto al medio ambiente frente a la amenaza ambiental industrial minera.

Si se tratase del fin de un sueño, lo que aparece por el momento ausente es el sueño que reemplace al anterior. En otras palabras, la desilusión producida por un sueño incumplido podría no ser suficiente para suponer que haya otro sueño alternativo. Sólo cuando el desmontaje de esta Lima que conocemos esté terminando será posible ver o entrever las bases de otro sueño posible. (Montoya 2020: 117).

\section{Conclusiones}

La crisis sanitaria en nuestro país refleja las tareas pendientes que el gobierno viene adeudándole a la población, relacionadas fundamentalmente con la falta de garantía de ciertos derechos básicos y sociales como la salud, educación, trabajo, seguridad, principalmente. Esta situación resulta una oportunidad para tocar estos temas de fondo y colocarlos dentro de las discusiones políticas, en el Parlamento, en el Ejecutivo, en las instituciones académicas, entre los alumnos y las personas en general; con el objetivo de participar de forma vigilante y fiscalizadora ante la inacción y falta de compromiso social del Estado para resolverlas.

Los autores analizados en el presente artículo convergen en la necesidad de replantearse la discusión sobre la pertinencia del neoliberalismo en la actualidad y la urgencia de difundir un pensamiento crítico ante las consecuencias negativas que implica la permanencia del estado actual de la política, basada en la conformación de una institucionalidad que satisface los intereses de una clase social de élite que busca enriquecerse a costa de las deficientes condiciones de vida de las mayorías.

Cabe resaltar que se ha analizado también, a manera de contrastar con las posturas de los demás autores, el discurso que Abusada difunde con respecto a la concepción neoliberal, quien niega su existencia debido a que alega que la presencia del Estado en forma institucional a través de todos los niveles de gobierno es un hecho real, pero no aporta eficientemente a la solución de los problemas fundamentales de la economía y sociedad en nuestro país, sino que más bien se colocan trabas burocráticas, se carece de productividad y voluntad política, además de acusar al gobierno de ser el principal agente de corrupción en nuestro país. La opinión del autor tiende la limitar las funciones del sector empresarial a la de agentes con capacidad de abastecimiento de bienes y servicios en los mercados y generadores de riqueza y empleo; pero que los asuntos políticos le competen únicamente al Estado como actor y responsable de la pobreza, la desigualdad de oportunidades y todos los males sociales persistentes hasta la actualidad.

Con respecto a lo mencionado es necesario, específicamente dentro la comunidad académica, fomentar la capacidad de reconocimiento de las diversas posturas que se refieren al neoliberalismo, a fin de poder utilizar las herramientas adecuadas que cada uno decida, según su criterio, las cuales puedan servir de instrumento para abordar la problemática social, económica y política que deja a su paso la crisis sanitaria en nuestro país.

\section{Recomendaciones}

En suma, ante lo discutido, queda claro que resulta necesario plantearse posibles escenarios de acción frente a la crisis sanitaria. El primero se inclina a seguir aguardando esperanzas hacia el gobierno de turno, y el segundo más bien a asumir una postura realista y comprometida con la realidad económica y social, para que desde la posición laboral o académica en la que nos encontremos se pongan mayores esfuerzos en realizar aportes significativos con el objetivo de promover una transformación política que 
permita que propuestas alternativas a las tradicionales que ostentan el poder, puedan aspirar a ocupar cargos públicos donde demuestren su capacidad de compromiso con valores colectivos, solidarios y progresistas.

Para ello, es necesario atender a las condiciones económicas y sociales que la pandemia está dejando a su paso, como por ejemplo los altos niveles de déficit fiscal producto de los gastos sociales incurridos por el gobierno durante los seis meses que van de transcurridos del Estado de Emergencia sanitaria, así como de pronósticos que indican que el Producto Bruto Interno aspiraría a lo mucho a un crecimiento anual a ritmo de $2 \%$ aproximado para el año 2021 debido a la lenta recuperación productiva que los sectores de turismo, minería y pesca, principalmente, tendrían para el siguiente año. Además de ello, una de las principales preocupaciones que enfrentaría el gobierno sería el alto nivel de desempleo producto de la informalidad, sector que ha sido el más golpeado durante toda la cuarentena sanitaria.

La informalidad, cabe resaltar, debe ser asunto de primera línea para el presente y futuro gobierno; si se quiere y se tiene intenciones de enfrentar el problema de raíz y a fondo, evitando caer en promesas populistas que maquillan una realidad de crecimiento económico sostenido, que la pandemia se ha encargado de develar como poco creíble.

Planes de reactivación económica dirigidos a formalizar a los comerciantes, otorgamientos de incentivos para la formalización y permisos para acceder a créditos a bajo costo a fin de insertarlos de forma adecuada al sistema económico del país, la oportunidad de contratar y capacitar a trabajadores para que desarrollen las mejores habilidades en favor del incremento de la calidad de los bienes y servicios producidos elevando su valor agregado y las ganancias; deben encontrarse dentro de las propuestas de reforma del sistema económico para corregir a la informalidad.

Por otro lado, es necesaria una reforma tributaria que se encargue de eliminar las exoneraciones que el gobierno otorga a las grandes corporaciones para ir avanzando hacia una democracia de mercado, que no perjudique a los pequeños negocios a costa de favorecer a ciertos grupos económicos de poder en el mercado. Más allá de ello, el gobierno tiene la tarea de recuperar sus ingresos fiscales corrientes a través del cobro pendiente de los tributos de las grandes empresas en el país; a fin de elevar la presión tributaria y aspirar a superar la cifra actual que va de entre el $14 \%$ a $15 \%$ de recaudación como porcentaje del PBI; cifra insuficiente si se desea rápida recuperación económica.

Con respecto al sistema de salud, se propone una reforma total del sistema, la cual deba relacionar al sector público con el privado, en base a una legislación común que establezca las mismas condiciones para cada sector, respetando la libertad de iniciativa empresarial privada, pero poniendo por delante la garantía del derecho a la salud de forma equitativa para todos los peruanos. La mayor inversión en ciencia y tecnología debe formar parte de las reformas de salud propuestas. El ciudadano y el Estado se encuentran en la obligación de priorizar el cuidado de la salud, por encima de cualquier necesidad del mercado, entendiendo la lógica elemental de que un ciudadano que previene enfermedades e invierte tiempo y atención a su salud, es un sujeto con mayores posibilidades de aspirar a un progreso económico y social, que repercuta en el incremento de los niveles económicos y productivos del país.

La actual crisis económica y social producto de la pandemia es una oportunidad dolorosa pero necesaria que pone en tela de juicio aquellos preceptos y paradigmas que promueven al neoliberalismo, para poder enfrentar con razones realistas y objetivas tales discursos que promueven su inexistencia. Es el momento para demostrar que las desigualdades sociales no pueden seguir escondiéndose debajo de agregados macroeconómicos, ni opiniones provenientes de intelectuales orgánicos defensores del libre mercado a ultranza, los cuales intentan evitar la modificación del status quo del cual se han aprovechado los grandes monopolios durante estos últimos treinta ańos.

Es momento también que los próximos actores políticos pongan al ciudadano y la garantía de sus derechos constitucionales, así como la preservación del medio ambiente y sus recursos, en primer orden dentro de las políticas públicas. Debido a ello, las propuestas presentadas en el presente artículo constituyen un aporte en el camino hacia una verdadera democracia y justicia social dentro del marco de un Estado de Derecho genuino. 


\section{Bibliografía}

Abusada, R. (14 de noviembre de 2019). ¿Perú Neoliberal? Obtenido de Instituto Peruano de Economía: https:// www.ipe.org.pe/portal/peru-neoliberal/

Cueto, M. (27 de marzo de 2020). La Covid-19 y las epidemias del neoliberalismo. Obtenido de Instituto de Estudios Peruanos: https://iep.org.pe/noticias/articulo-la-covid-19-y-las-epidemias-del-neoliberalismopor-marcos-cueto/

Diario Gestión. (s.f.). Obtenido de https://gestion.pe/ economia/fmi-mejora-proyeccion-para-economia-peruana-en-el-2021-noticia/?ref=gesr

Diario Perú 2i. (11 de Agosto de 2020). Obtenido de https://peru21.pe/lima/se-han-cometido-37-feminicidios-durante-en-lo-que-va-la-cuarentena-segun-informo-walter-martos-mimp-nndc-noticia/

Durand, A. (9 de abril de 2020). Coronavirus y neoliberalismo en el Perú. Obtenido de Centro Estratégico Latinoamericano de Geopolítica : https://www.celag. org/coronavirus-y-neoliberalismo-en-el-peru/
Lynch, N. (04 de junio de 2020). Los futuros posibles e imposibles de la pandemia. Obtenido de Otra Mirada: http://www.otramirada.pe/los-futuros-posibles-eimposibles-de-la-pandemia

Marañon, A. (19 de abril de 2020). Un mes de cuarentena en Perú: anormalidad, Estado y neoliberalismo. Obtenido de Consejo Latinoamericano de Ciencias Sociales: https://www.clacso.org/un-mes-de-cuarentena-en-peru-anormalidad-estado-y-neoliberalismo/

Montoya, R. (2020). Aquí Termina Lima. En El Coronavirus y su impacto en la sociedad actual y futura (págs. 115-118). Lima: Colegio de Sociologos del Perú.

Organización Mundial de la Salud (2020). Documentos técnicos de la OPS - Enfermedad por el Coronavirus (COVID-19).

Organización Panamericana de la Salud (s.f.). Cuidado y autocuidado de la salud mental en tiempos de COVID-19. Obtenido de https://www.paho.org/per/ index.php?option=com_content \&view=article \&id= 4546:cuidado-y-autocuidado-de-la-salud-mental-entiempos-de-covid-19\&Itemid $=1062$

Sala Situacional Covid-19 Perú. (2020). Obtenido de https://covid19.minsa.gob.pe/sala_situacional.asp 